\title{
Association between Afterhours Discharge from the Intensive Care Unit and Hospital Mortality: A Multi- Centre Retrospective Cohort Study
}

\section{Adam Hall}

University of Alberta

\section{Xioaming Wang}

Alberta Health Services

Danny J Zuege

Alberta Health Services

Dawn Opgenorth

University of Alberta

Damon C Scales

University of Toronto

Henry T Stelfox

University of Calgary

Sean M Bagshaw ( $\nabla$ bagshaw@ualberta.ca )

University of Alberta

Research

Keywords: afterhours, discharge, intensive care, mortality, quality, health services

Posted Date: August 4th, 2020

DOl: https://doi.org/10.21203/rs.3.rs-52238/v1

License: (9) This work is licensed under a Creative Commons Attribution 4.0 International License.

Read Full License

Version of Record: A version of this preprint was published at Journal of Intensive Care Medicine on February 25th, 2021. See the published version at https://doi.org/10.1177/0885066620981902. 


\section{Abstract}

Background: There is conflicting evidence on the association between afterhours discharge from the intensive care unit (ICU) and hospital mortality. We examined the effects of afterhours discharge, including the potential effect of residual organ dysfunction, on hospital mortality in a large integrated health region.

Methods: We performed a multi-centre retrospective cohort study of 10,463 adults discharged from nine mixed medical/surgical ICUs in Alberta from June 2012 to December 2014. We applied a two-stage modelling strategy to investigate the association between afterhours discharge (19:00h to 07:59h) and post-ICU hospital mortality. We applied mixed-effect multi-variable linear regression to assess the relationship between discharge organ dysfunction and afterhours discharge. We then applied mixedeffect multi-variable logistic regression to evaluate the direct, indirect and integrated associations of afterhours discharge on hospital mortality and hospitalization duration.

Results: Of 10,463 patients, $23.7 \%(n=2,480)$ were discharged afterhours, of which $27.4 \%$ occurred on a holiday or weekend. This varied significantly by ICU size, type, and site. Patients discharged afterhours were more likely medical admissions, had greater multi-morbidity and illness acuity. Greater SOFA score in the 72 hours prior to discharge was not associated with afterhours discharge; however, was associated with hospital mortality (adjusted-OR 1.23; 95\% Cl,1.18-1.28). Afterhours discharge was associated with higher hospital mortality (adjusted-OR 1.19; 95\% Cl, 1.01-1.39), increased hospital stay (adjusted-OR 1.10; 95\% Cl,1.09-1.11) and increased post-ICU stay (adjusted-OR 1.16; 95\%Cl,1.14-1.17).

Conclusions: Afterhours discharge is common, occurring in 1 in 4 discharges, and is widely variable across ICUs. Patients discharged afterhours have greater risk of hospital mortality and prolonged hospitalization.

\section{Background}

The structure and organization of intensive care unit (ICU) services may exert independent effects on patient outcomes and health services use. The points of admission, transfer and discharge to and from ICU represent high-risk periods in the care trajectory of critically ill patients. ${ }^{1}$ During afterhours periods, differences in health system structures such as nurse-to-patient ratios, in-house physician coverage, and availability of multidisciplinary teams may contribute to subtle but clinically important conditions that modify patient risk. ${ }^{2,3}$ Similarly, strained ICU capacity may synergistically modify care processes for discharges that occur afterhours, such as provoking premature discharges prior to resolution of acute organ dysfunction, and thereby increase patient risk for adverse outcomes. ${ }^{4}$

Afterhours ICU discharge has shown variable association with patient outcomes. ${ }^{5-13} \mathrm{~A}$ recent metaanalysis inferred that afterhours discharge was associated with higher risk for in-hospital mortality ${ }^{14}$, an effect consistent across varying definitions of afterhours, patient populations, case-mix, and healthcare 
delivery models. Patient factors, such as age ${ }^{13}$, chronic diseases ${ }^{5,6,15}$, residual organ dysfunction ${ }^{8,9}$, and limitations in care $8,9,12$ may also contribute to the higher mortality risk associated with patient discharge afterhours; however, associations with these factors have been inconsistent. $8,9,12$

Better understanding of the patient and healthcare system factors predisposing to afterhours discharges can help identify patients at greater risk and facilitate interventions (i.e., care processes) to mitigate this risk. Accordingly, we performed a retrospective cohort study to explore the relationship between afterhours discharge and patient outcomes in a large Canadian health region. We hypothesized that patient discharges occurring afterhours would be relatively common, would be modified by measures of strained ICU capacity reflected in greater unresolved organ dysfunction, and would be associated with higher mortality.

\section{Methods}

This study was approved by the Research Ethics Board at the University of Alberta, Edmonton, Canada (File \# Pro00046184). The need for written informed consent was waived.

\section{Study Design, Setting, and Population}

This was a multi-centre retrospective cohort including all adult patients $(n=10,463)$ surviving to ICU discharge between June 2012 and December 2014, the period of time during which a large provincial data extraction for all patients admitted to all ICUs in nine acute care hospitals in Edmonton and Calgary, Alberta. ${ }^{16}$ For patients with multiple ICU admissions, only the first admission was analyzed. The included ICUs were nine mixed medical/surgical units with a median [IQR] of 24 [10-28] beds. Two units were classified as academic/quaternary, two were academic/tertiary units, and five were community/metropolitan units (Table 1). All included ICUs operated with a "closed" model and were staffed by certified intensivists who are present and available during daytime hours, and available afterhours on-call.

\section{Data Sources}

Data were analyzed from eCritical Alberta, a provincial clinical information system, data warehouse and clinical analytics system. ${ }^{17}$ eCritical is a bedside interdisciplinary electronic documentation system (MetaVision ${ }^{\mathrm{TM}}$, iMDsoft) which captures demographic, diagnostic/case-mix (i.e., comorbidity, diagnostic classification, surgical status, Acute Physiology and Chronic Health Evaluation [APACHE] II and III score), Sequential Organ Failure Assessment (SOFA) score, Therapeutic Intervention Scoring System (TISS) 28 score, laboratory, and device data (physiologic monitors, ventilators, renal replacement therapy, use of vasoactive medications). TRACER is a comprehensive, multi-modal and integrated data repository and clinical analytics system. The eCritical Alberta system provides high-quality data due to rigorous data quality assurance and auditing processes and has been used by our team previously in health services research., ${ }^{48-21}$ There were no missing data elements for our primary exposure and outcome (afterhours 
discharge and hospital mortality, respectively). Missing data for individual variables were $<3 \%$ and were not replaced or imputed.

\section{Main Exposure and Outcomes}

The primary exposure was afterhours ICU discharge, defined as occurring between 19:00-07:59h. ${ }^{5}$ The primary outcome was all-cause post-ICU hospital mortality. Secondary outcomes included in-hospital mortality within 3 days, 7 days, and 14 days of discharge, ICU readmission at 48- and 72-hours, and total hospital and post-ICU hospital length of stay. Organ dysfunction at the time of ICU discharge was quantified by the average SOFA score in the 72 hours preceding ICU discharge. Additional variables included: age, sex, case-mix (e.g., diagnostic classification, surgical status, comorbidities, and Charlson comorbidity index, use of renal replacement therapy or vasoactive infusions), ICU-care variables (e.g., TISS-28 score 72 hours prior to discharge, percentage of days receiving DVT prophylaxis or stress ulcer prophylaxis, duration of intubation and mechanical ventilation, unplanned extubation) and ICU site (e.g., location, hospital type).

\section{Statistical Analysis}

Data were initially explored descriptively. Normally or near-normally distributed data were reported as mean (SD) while non-normally distributed continuous data were reported as median (IQR). Comparisons were by Student's T-test or Wilcoxon-Mann-Whitney U-test, respectively. Categorical variables were reported as frequency (percentage) and compared by Chi-squared test.

Path-analysis modelling: We proposed a two-stage modelling strategy to evaluate the direct, indirect, and integrated associations between afterhours discharge, illness severity (e.g., organ dysfunction at ICU discharge), and hospital mortality (Additional File 1). We used a path-analysis strategy to better explore hypothesized relationships that may both directly and indirectly modify the potential causal association between afterhours discharge and in-hospital mortality.,22-24 First, we used random-effects multi-variable linear regression to quantify the association between discharge organ dysfunction and afterhours discharge (Additional File 2). Second, we used random-effects multi-variable logistic regression to evaluate the association between discharge organ dysfunction and afterhours discharge on hospital mortality. We assumed that discharge organ dysfunction varied by ICU, so ICU site was used as a random-effects predictor. A sparse model was created by stepwise variable selection for multi-variable modelling analyses. ${ }^{25}$ SAS (release 9.4; SAS Institute, Cary, NC) was used for all modelling analyses. Finally, we proposed to estimate the integrated effect by combining the direct and indirect effects of afterhours discharge on hospital mortality, conditional on finding significant association between discharge organ dysfunction and afterhours discharge, in simulation experiments (1 million replicates) via $\mathrm{R}$ Core ${ }^{26}$.4,22 The association between afterhours discharge, discharge organ dysfunction, and lengths of stay were further evaluated using random-effects multi-variable Poisson regression (Additional Files 3 and 4). 
Exploratory Subgroup and Sensitivity Analysis: Sensitivity analysis utilized the same modelling process as our primary analysis, and examined afterhours discharge utilizing different definitions of afterhours discharge (i.e., 19:00-06:59, 19:00-08:59, 19:00-09:59, 20:00-06:59, 21:00-06:59, and 22:00-06:59 and by ICU site), as well as indicators of strained ICU capacity, afterhours discharge on non-work day, afterhours discharge when occupancy $\geq 90 \%$, and afterhours discharge with clustering of admissions $\geq 2$. Clustering of admissions was defined as the number of admissions in the two hours before or after the index admission, divided by the number of funded ICU beds. ${ }^{16}$

\section{Results}

\section{Afterhours ICU Discharge}

A total of 10,463 patients were discharged alive during the study period, of which, $23.7 \%(n=2,480)$ occurred afterhours. The afterhours discharge rates were variable across ICUs, ranging from $9.2 \%$ to $32.2 \%$ (Figure 1). Of patients discharged afterhours, $27.4 \%$ occurred on a holiday or weekend. Afterhours discharge was more common in academic/teaching ICUs, in larger ICUs and during periods of higher occupancy (Table 1). Afterhours discharges were also associated with a higher average occupancy and numbers of daily ICU admissions and discharges (Table 2). Patients discharged afterhours were more likely to be medical admissions, have higher prevalence of selected comorbid conditions, have higher admission illness acuity, had received greater organ support, and have higher average daily SOFA and TISS-28 scores (Table 1).

\section{Association between Afterhours ICU Discharge and SOFA Score}

In multivariable analysis, there was no significant association between afterhours ICU discharge and average SOFA score in the 72 hours prior to discharge (adjusted-odds ratio [OR] 0.97; 95\% $\mathrm{Cl}, 0.90-1.04$, $\mathrm{p}=0.40$ ) (Additional File 1). As such, the indirect effects discharge organ dysfunction, measured by average SOFA score at ICU discharge, were omitted from the final path-analysis model and only the direct effects are reported.

\section{Association between Afterhours ICU Discharge and Hospital Mortality}

Post-discharge hospital mortality was $7.7 \%(n=803)$. In multivariable analysis, afterhours ICU discharge remained associated with increased odds for hospital mortality (adjusted-OR 1.19; 95\% Cl, 1.01-1.39) (Table 3; Additional File 2; Table 4). Several factors, including age, medical diagnosis, neurological diagnosis, admission APACHE II score, and average SOFA score in the 72 hours prior to discharge were independently associated with hospital mortality.

Association between Afterhours ICU Discharge and ICU Readmission and Lengths of Stay

Readmission at 48 and 72 hours occurred in $0.9 \%(n=95)$ and $1.5 \%(n=156)$ of ICU discharges, respectively. There were no significant differences in readmission rates by ICU discharge time (Table 3; 
Additional Files 4 and 5). Afterhours ICU discharge was associated with longer total hospital and post-ICU hospital lengths of stay (Table 3). The association with longer total and post-ICU hospital stay remained significant in multivariable analysis (Supplementary Tables 2 and 3 ).

\section{Exploratory Subgroup and Sensitivity Analysis}

There were no differences in hospital mortality stratified by ICU type (Table 5). Exploratory analyses of the direct effects of afterhours discharge showed no substantial evidence with time of death in multivariable adjustment (Additional Files 6-9).

\section{Discussion}

We performed a multi-centre cohort study to describe the incidence, correlates and outcomes associated with patient discharges from the ICU occurring afterhours. We found approximately 1 in 4 patients were discharged afterhours, though we found wide variability in rates across ICUs. Patients supported in academic/teaching ICUs, in ICUs with greater occupancy and in ICUs with higher average number of daily discharges were more likely to be discharged afterhours. These patients were also more likely to be nonsurgical, have a greater burden of chronic disease and have greater illness acuity and organ support during ICU admission. We also found that patients who experienced discharge from ICU afterhours had greater risk for hospital mortality and longer duration of hospitalization, but no greater risk for early ICU readmission. We suggest that such adverse outcomes may be time- and/or context-sensitive and influenced substantially by factors that are not patient-related. These observations contribute additional knowledge to the growing body of literature to suggest that ICU organization and the process of care transitions occurring afterhours may potentially modify patient outcomes and health services utilization.

\section{Context with Prior Literature}

The afterhours ICU discharge of patients appears to be an omnipresent practice, occurring with greater frequently in our large Canadian health region than described in other jurisdictions $s^{6-10,12,15}$ and exhibiting an increasing trend over time ${ }^{5,27}$ Afterhours discharges would appear predominantly driven by trends in larger academic/tertiary hospitals. This practice would be acceptable to patients, their families and healthcare professionals provided it is organized, planned and proven safe $\mathrm{e}^{1}$; however, this is not supported by evidence. It remains unclear whether the process of afterhours care transitions is embedded in policy or whether this is more a consequence of changing acute care services delivery and strained hospital occupancy.

Prior studies have shown conflicting association between afterhours discharge and adverse patient outcomes; however, studies varied markedly in design, setting, case-mix, definitions of afterhours, health systems organization, and analytic approach. 5,7-12,14,15,28 Consistent with prior work, our study including all ICUs in an large integrated health region, found selected patient-related factors portend greater mortality risk with afterhours discharge including multi-morbidity, illness acuity and medical 
admission. 5,6,15 Unresolved or residual organ dysfunction at the time of ICU discharge has shown greater susceptibility to mortality and/or ICU readmission and may be suggestive that such discharges are "premature". 5,15,29,30 In a retrospective single centre study, patient discharged afterhours were found to have greater APACHE II scores upon transfer. ${ }^{8}$ In this study, higher acuity was not associated with mortality; however, few patients (only $3.6 \%$ ) were discharged afterhours. In contrast, in a multi-centre study, greater residual organ dysfunction at ICU discharge, as measured by SOFA score, specifically neurological and kidney dysfunction, was associated with increased hospital mortality. ${ }^{29}$ In our study, average SOFA score in the 72 hours prior to discharge was marginally higher for those discharged afterhours and did show association with greater hospital mortality. However, in multivariable analysis, discharge organ dysfunction did not show association with being discharged afterhours.

There is likely no patient-centered rationale for an ICU-to-ward transfer to occur afterhours, except perhaps when it facilitates a shift to palliative end-of-life care in a more suitable environment and when death would be expected. ${ }^{6}$ This is indirectly supported by a large prospective study suggesting no effect of afterhours discharge on risk of hospital mortality after adjustment for "orders to limit medical care."12 Indeed, limitations of medical therapy at ICU discharge (i.e., not for ICU readmission) may be a confounder of the association of afterhours discharge and hospital mortality during lower ICU occupancy and during workdays, as shown in our study. It is probable the practice of afterhours discharge is mainly propelled by ICU and hospital capacity-related issues. ${ }^{31,32}$ These may include no ward bed availability during daytime hours and delays in planned transfers or conditions of strained ICU capacity prompting unplanned ("premature") discharges. 6,12

\section{Limitations}

While our study was large, multi-centric and leveraged prospectively collected and robust patient ICU-level data, it does have limitations. First, despite a proposed path-analysis and multi-variable adjustment, our study remains susceptible to residual confounding. Second, we were not able to capture specific information on the "reasons" for ICU discharge afterhours and have indirectly inferred whether this may have been attributable to strained ICU conditions. Similarly, we did not have data on whether hospital wards were experiencing strained capacity at the time of ICU discharge. Third, we did not have data on the goals-of-care status for patients at the time of ICU discharge. While a prior study found limitations of medical therapy confounds the association of afterhours discharge and mortality ${ }^{12}$; other studies have found that strained ICU capacity was associated with reduced time to initiating limitations of medical therapy (i.e., do-not-resuscitate) in ICU ${ }^{22}$ and increased likelihood of changing goals of care for deteriorating patients on the ward. ${ }^{33}$ Finally, the ICU readmission rate in our study was notably low and was not found to be substantially different by ICU discharge time; however, we recognize that ICU readmission may have limitations as a quality indicator due to challenges in adjudicating whether readmissions were avoidable. ${ }^{34}$

Implications for Policy 
The practice of afterhours discharge is modifiable and has been identified as a key quality and performance indicator for measuring, monitoring and benchmarking both within and between institutions. ${ }^{35}$ Some have suggested that afterhours discharge be reportable as an adverse event. ${ }^{36}$ Regardless, as with any quality indicator, ICUs should undertake root cause analyses to understand the circumstances for their rates of afterhours discharge, given its robust association with mortality. We submit that hospitals should aim to develop policy, guidelines and/or procedures to avoid unwarranted afterhours discharge and to mitigate unnecessary risks to patients who happen to experience ICU discharge afterhours.

\section{Conclusions}

Afterhours discharge is common, occurring in 1 in 4 discharges, has shown increasing trends, and is widely variable across ICUs. Patients discharged afterhours have greater risk of hospital mortality and prolonged hospitalization. ICU-to-ward discharges occurring afterhours are modifiable care processes and may be more driven by issues of health system organization rather that patient-specific factors. These data should reinforce the value measuring afterhours discharges, of developing standard policy and procedures, and for identifying patient most at-risk of potentially avoidable harm attributed to afterhours discharge.

\section{Declarations}

Ethics approval and consent to participate: This study was approved by the Research Ethics Board at the University of Alberta, Edmonton, Canada (File \# Pro00046184). The need for written informed consent was waived.

Consent for publication: not applicable.

Availability of data and material: The data to support this study was provided by the eCritical Program and Alberta Health Services. Data are available from the authors upon reasonable request and with permission of Alberta Health Services.

Competing Interests: SMB is supported by a Canada Research Chair in Critical Care Nephrology. HTS is supported by CIHR Embedded Clinician Researcher Award.

Funding: This work was funded by a Partnership for Research and Innovation in the Health System (PRIHS) grant, Alberta Innovates - Health Solutions (Grant Record Number: 201300467). The funding agency had no role in the design or conduct of the study, in the collection, management, analysis or interpretation of the data, or in the preparation, review or approval of the manuscript.

Authors' contributions: AMH analyzed data, interpreted data, drafted the manuscript with support from SMB, and provided critical revision of the manuscript. HTS conceived the study, obtained funding for the study, interpreted data, and provided critical revision of the manuscript. XW analyzed the data, performed 
the simulation experiments, interpreted data and provided critical revision of the manuscript. DZ obtained data, interpreted data and provided critical revision of the manuscript. DCS interpreted data and provided critical revision of the manuscript. DO interpreted data and provided critical revision of the manuscript. SMB conceived the study, obtained funding for the study, obtained data, analyzed the data, interpreted data, and provided critical revision of the manuscript.

Acknowledgements: Not applicable.

Authors' Information: SMB is supported by a Canada Research Chair in Critical Care Nephrology. HTS is supported by a CIHR Embedded Clinician Researcher Award

Disclosures: Dr. Bagshaw is supported by a Canada Research Chair in Critical Care Nephrology. Dr. Stelfox is supported by CIHR Embedded Clinician Researcher Award.

Funding/Support: Funded by a Partnership for Research and Innovation in the Health System (PRIHS) grant, Alberta Innovates - Health Solutions (Grant Record Number: 201300467).

\section{References}

1. Stelfox HT, Leigh JP, Dodek PM, et al. A multi-center prospective cohort study of patient transfers from the intensive care unit to the hospital ward. Intensive Care Med 2017;43:1485-94.

2. Aiken LH, Clarke SP, Sloane DM, Sochalski J, Silber JH. Hospital nurse staffing and patient mortality, nurse burnout, and job dissatisfaction. JAMA 2002;288:1987-93.

3. West E, Barron DN, Harrison D, Rafferty AM, Rowan K, Sanderson C. Nurse staffing, medical staffing and mortality in Intensive Care: An observational study. Int J Nurs Stud 2014;51:781-94.

4. Bagshaw SM, Wang X, Zygun DA, et al. Association between strained capacity and mortality among patients admitted to intensive care: A path-analysis modeling strategy. J Crit Care 2018;43:81-7.

5. Azevedo LC, de Souza IA, Zygun DA, Stelfox HT, Bagshaw SM. Association Between Nighttime Discharge from the Intensive Care Unit and Hospital Mortality: A Multi-Center Retrospective Cohort Study. BMC Health Serv Res 2015;15:378.

6. Duke GJ, Green JV, Briedis JH. Night-shift discharge from intensive care unit increases the mortalityrisk of ICU survivors. Anaesth Intensive Care 2004;32:697-701.

7. Gantner D, Farley K, Bailey M, Huckson S, Hicks P, Pilcher D. Mortality related to after-hours discharge from intensive care in Australia and New Zealand, 2005-2012. Intensive Care Med 2014;40:1528-35.

8. Hanane T, Keegan MT, Seferian EG, Gajic O, Afessa B. The association between nighttime transfer from the intensive care unit and patient outcome. Crit Care Med 2008;36:2232-7.

9. Laupland KB, Misset B, Souweine B, et al. Mortality associated with timing of admission to and discharge from ICU: a retrospective cohort study. BMC Health Serv Res 2011;11:321.

10. Pilcher DV, Duke GJ, George C, Bailey MJ, Hart G. After-hours discharge from intensive care increases the risk of readmission and death. Anaesth Intensive Care 2007;35:477-85. 
11. Priestap FA, Martin CM. Impact of intensive care unit discharge time on patient outcome. Crit Care Med 2006;34:2946-51.

12. Santamaria JD, Duke GJ, Pilcher DV, et al. The timing of discharge from the intensive care unit and subsequent mortality. A prospective, multicenter study. Am J Respir Crit Care Med 2015;191:1033-9.

13. Singh MY, Nayyar V, Clark PT, Kim C. Does after-hours discharge of ICU patients influence outcome? Crit Care Resusc 2010;12:156-61.

14. Vollam S, Dutton S, Lamb S, Petrinic T, Young JD, Watkinson P. Out-of-hours discharge from intensive care, in-hospital mortality and intensive care readmission rates: a systematic review and metaanalysis. Intensive Care Med 2018;44:1115-29.

15. Goldfrad C, Rowan K. Consequences of discharges from intensive care at night. Lancet 2000;355:1138-42.

16. Hall AM, Stelfox HT, Wang X, et al. Association between afterhours admission to the intensive care unit, strained capacity, and mortality: a retrospective cohort study. Crit Care 2018;22:97.

17. Brundin-Mather R, Soo A, Zuege DJ, et al. Secondary EMR data for quality improvement and research: A comparison of manual and electronic data collection from an integrated critical care electronic medical record system. J Crit Care 2018;47:295-301.

18. Australian PIft, New Zealand Intensive Care Society Clinical Trials Group AHSCCSCN, the Irish Critical Care Trials G, et al. Effect of Stress Ulcer Prophylaxis With Proton Pump Inhibitors vs Histamine-2 Receptor Blockers on In-Hospital Mortality Among ICU Patients Receiving Invasive Mechanical Ventilation: The PEPTIC Randomized Clinical Trial. JAMA 2020.

19. Stelfox HT, Brundin-Mather R, Soo A, et al. A multicentre controlled pre-post trial of an implementation science intervention to improve venous thromboembolism prophylaxis in critically ill patients. Intensive Care Med 2019;45:211-22.

20. Stelfox HT, Soo A, Niven DJ, et al. Assessment of the Safety of Discharging Select Patients Directly Home From the Intensive Care Unit: A Multicenter Population-Based Cohort Study. JAMA Intern Med 2018;178:1390-9.

21. Tran DT, Thanh NX, Opgenorth D, et al. Association between strained ICU capacity and healthcare costs in Canada: A population-based cohort study. J Crit Care 2019;51:175-83.

22. Hua M, Halpern SD, Gabler NB, Wunsch H. Effect of ICU strain on timing of limitations in lifesustaining therapy and on death. Intensive Care Med 2016;42:987-94.

23. Pearl D, Mackenzie D. The Book of Why: The New Science of Cause and Effect. New York: Basic Books; 2019.

24. Wright S. The method of path coefficients. Ann Math Statist 1934;5.

25. Hicks R, D. T. Causal Mediation Analysis. The Stata Journal 2011;11.

26. Language for Statistical Computing. 2013.

27. Zajic P, Bauer P, Rhodes A, et al. Time of Day and its Association with Risk of Death and Chance of Discharge in Critically III Patients: A Retrospective Study. Sci Rep 2019;9:12533. 
28. Uusaro A, Kari A, Ruokonen E. The effects of ICU admission and discharge times on mortality in Finland. Intensive Care Med 2003;29:2144-8.

29. Moreno R, Miranda DR, Matos R, Fevereiro T. Mortality after discharge from intensive care: the impact of organ system failure and nursing workload use at discharge. Intensive Care Med 2001;27:999-1004.

30. Rodriguez-Carvajal M, Mora D, Doblas A, et al. [Impact of the premature discharge on hospital mortality after a stay in an intensive care unit]. Med Intensiva 2011;35:143-9.

31. Chrusch CA, Olafson KP, McMillan PM, Roberts DE, Gray PR. High occupancy increases the risk of early death or readmission after transfer from intensive care. Crit Care Med 2009;37:2753-8.

32. Wagner J, Gabler NB, Ratcliffe SJ, Brown SE, Strom BL, Halpern SD. Outcomes among patients discharged from busy intensive care units. Ann Intern Med 2013;159:447-55.

33. Stelfox HT, Hemmelgarn BR, Bagshaw SM, et al. Intensive care unit bed availability and outcomes for hospitalized patients with sudden clinical deterioration. Arch Intern Med 2012;172:467-74.

34. Al-Jaghbeer MJ, Tekwani SS, Gunn SR, Kahn JM. Incidence and Etiology of Potentially Preventable ICU Readmissions. Crit Care Med 2016;44:1704-9.

35. Chrusch CA, Martin CM, Project TQ. Quality Improvement in Critical Care: Selection and Development of Quality Indicators. Can Respir J 2016;2016:2516765.

36. Guidet B, Bion J. Night thoughts. Intensive Care Med 2014;40:1586-8.

\section{Tables}

Table 1: Characteristics of patients and ICUs, stratified by time of discharge from ICU: workhour (08:0018:59) or afterhours (19:00-07:59). 


\begin{tabular}{|c|c|c|c|c|}
\hline Characteristic & $\begin{array}{l}\text { Total } \\
(n=10,463, \\
100 \%)\end{array}$ & $\begin{array}{l}\text { Workhours } \\
(n=7,983 \text {, } \\
76.3 \%)\end{array}$ & $\begin{array}{l}\text { Afterhours } \\
(n=2,480 \text {, } \\
23.7 \%)\end{array}$ & $\begin{array}{l}\mathrm{p}- \\
\text { value }\end{array}$ \\
\hline Age, median (IQR) & $\begin{array}{l}58.0(44.0- \\
69.0)\end{array}$ & $\begin{array}{l}58.0(44.0- \\
69.0)\end{array}$ & $\begin{array}{l}59.0(46.0- \\
69.0)\end{array}$ & 0.21 \\
\hline Age category, n (\%) & & & & 0.98 \\
\hline$<65$ years & $6,774(64.8)$ & $5166(64.7)$ & $1608(64.9)$ & \\
\hline $65-74$ years & 2,019 (19.3) & $1547(19.4)$ & $472(19.1)$ & \\
\hline $75-84$ years & $1,369(13.1)$ & $1041(13.1)$ & $328(13.2)$ & \\
\hline$\geq 85$ years & $296(2.8)$ & $226(2.8)$ & $70(2.8)$ & \\
\hline Sex, n (\%) & & & & 0.10 \\
\hline Female & $4,347(41.6)$ & $3281(41.1)$ & $1066(43.0)$ & \\
\hline System, n (\%) & & & & 0.07 \\
\hline Cardiovascular & $1,496(14.4)$ & $1117(14.1)$ & $379(15.4)$ & \\
\hline Gastrointestinal & $1,700(16.4)$ & $1295(16.3)$ & $405(16.5)$ & \\
\hline Genitourinary & $423(4.1)$ & $328(1.1)$ & $95(3.9)$ & \\
\hline Hematology & $52(0.5)$ & $41(0.5)$ & $11(0.5)$ & \\
\hline Metabolic/Endocrine & $238(2.3)$ & $181(2.3)$ & $57(2.3)$ & \\
\hline Musculoskeletal/Skin & $443(4.3)$ & $350(4.4)$ & $93(3.8)$ & \\
\hline Neurologic & $1,648(15.9)$ & $1211(15.3)$ & $437(17.8)$ & \\
\hline Respiratory & $3,176(30.6)$ & $2456(31.0)$ & $720(29.2)$ & \\
\hline Transplant & $126(1.2)$ & $99(1.3)$ & $27(1.1)$ & \\
\hline Trauma & $1,087(10.5)$ & $849(10.7)$ & $238(9.7)$ & \\
\hline Surgery, n (\%) & & & & $<0.001$ \\
\hline Elective & 1,183 (11.3) & $967(12.1)$ & $216(8.7)$ & \\
\hline Emergent & $1,827(17.5)$ & 1419 (17.8) & $408(16.5)$ & \\
\hline Non-operative & 7,451 (71.2) & $5597(70.1)$ & $1856(74.8)$ & \\
\hline Class, n (\%) & & & & $<0.001$ \\
\hline Medical & $5,985(57.2)$ & 4535 (56.8) & $1450(58.5)$ & \\
\hline Neurological & $678(6.5)$ & $450(5.6)$ & $228(9.2)$ & \\
\hline
\end{tabular}




\begin{tabular}{|c|c|c|c|c|}
\hline Surgical & $2,855(27.3)$ & $2273(28.5)$ & $582(23.5)$ & \\
\hline Trauma without head injury & $607(5.8)$ & $470(5.9)$ & $137(5.5)$ & \\
\hline Trauma with head injury & $338(3.2)$ & $255(3.2)$ & $83(3.4)$ & \\
\hline \multicolumn{5}{|l|}{ Comorbidity disease, n (\%) } \\
\hline Chronic Dialysis & $350(3.4)$ & $240(3.0)$ & $110(4.4)$ & $<0.001$ \\
\hline Hepatic & $882(8.4)$ & $650(8.1)$ & $232(9.4)$ & 0.06 \\
\hline Neurologic & $4,213(40.3)$ & $3114(39.4)$ & $1069(43.1)$ & 0.001 \\
\hline $\begin{array}{l}\text { Acute Immunodeficiency } \\
\text { Syndrome }\end{array}$ & $51(0.5)$ & $37(0.5)$ & $14(0.6)$ & 0.53 \\
\hline Chronic Heart Failure & $582(5.6)$ & $430(5.4)$ & $152(6.1)$ & 0.16 \\
\hline Respiratory & $1,174(11.2)$ & $912(11.4)$ & $262(10.6)$ & 0.24 \\
\hline Metastatic/Leukemia/Lymphoma & $621(5.9)$ & $484(6.1)$ & $137(5.5)$ & 0.32 \\
\hline Immune Suppression & $877(8.4)$ & $643(8.1)$ & $234(9.4)$ & 0.03 \\
\hline Diabetes & $1,891(18.1)$ & $1414(17.7)$ & $477(19.2)$ & 0.09 \\
\hline Cirrhosis & $584(5.6)$ & $427(5.4)$ & $157(6.3)$ & 0.06 \\
\hline Cardiovascular & $4,478(42.8)$ & $3347(41.9)$ & $1131(45.6)$ & 0.001 \\
\hline Digestive & $1,764(16.9)$ & $1330(16.7)$ & $434(17.5)$ & 0.33 \\
\hline Acute Renal & $2,166(20.2)$ & $1549(19.4)$ & $567(22.9)$ & $<0.001$ \\
\hline \multicolumn{5}{|l|}{ Charlson Index, } \\
\hline Median (IQR) & $1.0(0.0-2.0)$ & $1.0(0.0-2.0)$ & $1.0(0.0-2.0)$ & 0.002 \\
\hline Mean (SD) & $1.2(1.8)$ & $1.2(1.2)$ & $1.3(1.2)$ & 0.002 \\
\hline$\geq 1, \mathrm{n}(\%)$ & 3507 (33.5) & $2640(33.1)$ & $867(35.0)$ & 0.08 \\
\hline $\begin{array}{l}\text { Admission APACHE II score, mean } \\
\text { (SD) }\end{array}$ & $18.9(7.7)$ & $18.8(7.7)$ & $19.4(7.6)$ & $<0.001$ \\
\hline \multicolumn{5}{|l|}{ \#Percent Days on DVT prophylaxis, } \\
\hline median (IQR) & $100(100-100)$ & $100(100-100)$ & $100(88.9-100)$ & $<0.001$ \\
\hline mean $(S D)$ & $93.4(16.2)$ & $94.1(15.2)$ & $90.9(19.1)$ & $<0.001$ \\
\hline$\geq 95 \%, \mathrm{n}(\%)$ & 8031 (76.8) & $6320(79.2)$ & $1711(69.0)$ & $<0.001$ \\
\hline $\begin{array}{l}\text { \# Percent Days on PUD } \\
\text { prophylaxis, }\end{array}$ & $100(92.3-100)$ & $100(95-100)$ & $100(87.5-100)$ & $<0.001$ \\
\hline
\end{tabular}




\begin{tabular}{|c|c|c|c|c|}
\hline median (IQR) & $92.3(16.8)$ & $92.9(15.9)$ & $90.2(19.5)$ & $<0.001$ \\
\hline mean (SD) & $7646(73.1)$ & $5980(74.9)$ & $1666(67.2)$ & $<0.001$ \\
\hline \multicolumn{5}{|l|}{$\geq 95 \%, \mathrm{n}(\%)$} \\
\hline Vasoactive infusion, n (\%) & $3977(38.0)$ & $2997(37.5)$ & $980(39.5)$ & 0.08 \\
\hline Received RRT or dialysis, n (\%) & $7.9(6.8)$ & $506(6.3)$ & $203(8.2)$ & 0.001 \\
\hline IMV duration*, median (IQR) & $1.1(0.0-4.2)$ & $1.1(0.0-4.0)$ & $1.3(0.0-5.0)$ & $<0.001$ \\
\hline Intubation duration*, median (IQR) & $1.0(0-4.0)$ & $1.0(0.0-3.8)$ & $1.2(0.0-4.6)$ & $<0.001$ \\
\hline Unplanned Extubation, n (\%) & $254(2.43)$ & $187(2.34)$ & $67(2.70)$ & 0.31 \\
\hline Average SOFA Score, mean (SD)** & $4.05(1.79)$ & $4.02(1.74)$ & $4.14(1.96)$ & $<0.001$ \\
\hline 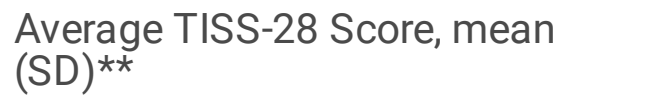 & $23.91(6.32)$ & $23.88(6.32)$ & $24.01(6.29)$ & $<0.001$ \\
\hline Hospital type & & & & $<0.001$ \\
\hline Academic & $4,897(46.8)$ & $3556(44.5)$ & $1341(54.1)$ & \\
\hline Tertiary & $3,131(29.9)$ & $2484(31.1)$ & $647(26.1)$ & \\
\hline Community & $2,435(23.3)$ & $1943(24.34)$ & $492(19.8)$ & \\
\hline ICUs, n (\%) & & & & $<0.001$ \\
\hline Academic 1 & $2,552(24.4)$ & $1731(21.7)$ & $821(33.1)$ & \\
\hline Academic 2 & $2,345(22.4)$ & $1825(22.9)$ & $520(21.0)$ & \\
\hline Tertiary 1 & $1,695(16.2)$ & $1485(18.6)$ & $210(8.5)$ & \\
\hline Tertiary2 & $1,436(13.7)$ & $999(12.5)$ & $437(17.6)$ & \\
\hline Community 1 & $1,072(10.3)$ & $825(10.3)$ & $247(10.0)$ & \\
\hline Community 2 & $581(5.6)$ & $442(5.5)$ & $139(5.6)$ & \\
\hline Community 3 & $292(2.8)$ & $265(3.3)$ & $27(1.1)$ & \\
\hline Community 4 & $253(2.4)$ & $197(2.5)$ & $56(2.3)$ & \\
\hline Community 5 & $237(2.3)$ & $214(2.7)$ & $23(0.9)$ & \\
\hline ICU size, median (IQR) & $\begin{array}{l}24.0(10.0- \\
28.0)\end{array}$ & $\begin{array}{l}24.0(10.0- \\
28.0)\end{array}$ & $\begin{array}{l}26.0(18.0- \\
28.0)\end{array}$ & $<0.001$ \\
\hline \multicolumn{5}{|l|}{ Bed occupancy at admission } \\
\hline Rate, median (IQR) & $\begin{array}{l}85.7(76.0- \\
92.3)\end{array}$ & $\begin{array}{l}85.7(75.0- \\
92.3)\end{array}$ & $\begin{array}{l}87.5(79.2- \\
92.9)\end{array}$ & $<0.001$ \\
\hline Occupancy Rate $\geq 90 \%$ & $3,501(34.3)$ & $2581(33.2)$ & $920(37.6)$ & $<0.001$ \\
\hline
\end{tabular}


Definition of abbreviation: APACHE=Acute Physiologic Assessment and Chronic Health Evaluation; DVT=deep vein thrombosis; ICU=intensive care unit; IMV=invasive mechanical ventilation; IQR=interquartile range; PUD=peptic ulcer disease; RRT =renal replacement therapy; SD=standard deviation; SOFA=Sequential Organ Failure Assessment; TISS=Therapeutic Intervention Scoring System.

*Both IMV duration and intubation duration were measured in 1000 minutes.

${ }^{\star} \star$ Average SOFA/TISS-28 score was patient average SOFA score on his/her whole period in ICU.

\#Days on DVT/PUD was a percentage of days on DVT/PUD prophylaxis over total days in ICU.

Table 2 ICU characteristics on the day of discharge, stratified by workhours or afterhours discharge.

\begin{tabular}{|c|c|c|c|c|}
\hline Effect & $\begin{array}{l}\text { Total } \\
(n=10463)\end{array}$ & $\begin{array}{l}\text { Workhours } \\
(n=7983)\end{array}$ & $\begin{array}{l}\text { Afterhours } \\
(\mathrm{n}=2480)\end{array}$ & $\begin{array}{l}\mathrm{p}- \\
\text { value }\end{array}$ \\
\hline Average occupancy rate* (\%) & & & & $<0.001$ \\
\hline Median (IQR) & $\begin{array}{l}84.2 \\
(73.8- \\
90.5)\end{array}$ & $\begin{array}{l}83.6(72.6- \\
90.2)\end{array}$ & $\begin{array}{l}85.7 \\
(76.2- \\
91.2)\end{array}$ & \\
\hline Mean (SD) & $\begin{array}{l}80.1 \\
(15.6)\end{array}$ & $\begin{array}{l}79.5 \\
(16.0)\end{array}$ & $\begin{array}{l}81.9 \\
(14.2)\end{array}$ & \\
\hline Number of admissions* $(n)$ & & & & $<0.001$ \\
\hline Median (IQR) & $3(1-4)$ & $3(1-4)$ & $3(2-4)$ & \\
\hline Mean (SD) & $2.9(1.9)$ & $2.9(1.9)$ & $3.0(2.0)$ & \\
\hline Number of discharges (n) & & & & 0.001 \\
\hline Median (IQR) & $3(2-5)$ & $3(2-4)$ & $3(2-5)$ & \\
\hline Mean (SD) & $3.4(1.7)$ & $3.4(1.7)$ & $3.5(1.8)$ & \\
\hline Average admission APACHE II score & & & & 0.42 \\
\hline Median (IQR) & $\begin{array}{l}18.5 \\
(15.5- \\
21.8)\end{array}$ & $\begin{array}{l}18.5(15.6- \\
21.8)\end{array}$ & $\begin{array}{l}18.5 \\
(15.5- \\
21.7)\end{array}$ & \\
\hline Mean (SD) & $18.6(5.2)$ & $18.7(5.1)$ & $18.6(5.2)$ & \\
\hline
\end{tabular}

Definition of abbreviation: APACHE=Acute

Physiologic Assessment and Chronic Health

Evaluation; $I Q R=$ interquartile range; $S D=$ standard deviation

*All values reported with an asterisk are as of the patient's day of discharge; i.e. average occupancy rate on patient's day of discharge. 
Table 3 Unadjusted hospital mortality for patients surviving to ICU discharge, ICU readmission, hospital LOS, and post-ICU LOS, stratified by workhours or afterhours discharge. 


\begin{tabular}{|c|c|c|c|c|}
\hline Effect & $\begin{array}{l}\text { Total } \\
(\%)\end{array}$ & $\begin{array}{l}\text { Workhours } \\
\text { n (\%) }\end{array}$ & $\begin{array}{l}\text { Afterhours } \\
\mathrm{n}(\%)\end{array}$ & $\begin{array}{l}\mathrm{p}- \\
\text { value }\end{array}$ \\
\hline Hospital mortality, after ICU discharge & $\begin{array}{l}803 \\
(7.7)\end{array}$ & $580(7.3)$ & $223(9.0)$ & 0.005 \\
\hline $\begin{array}{l}\text { Hospital mortality within } 3 \text { days, after ICU } \\
\text { discharge }\end{array}$ & $\begin{array}{l}193 \\
(1.8)\end{array}$ & $135(1.7)$ & $58(2.3)$ & 0.04 \\
\hline $\begin{array}{l}\text { Hospital mortality within } 7 \text { days, after ICU } \\
\text { discharge }\end{array}$ & $\begin{array}{l}325 \\
(3.1)\end{array}$ & $230(2.9)$ & $95(3.8)$ & 0.02 \\
\hline $\begin{array}{l}\text { Hospital mortality within } 14 \text { days, after ICU } \\
\text { discharge }\end{array}$ & $\begin{array}{l}469 \\
(4.5)\end{array}$ & $343(4.3)$ & $126(5.1)$ & 0.01 \\
\hline ICU Readmission within 48 hours & $95(0.9)$ & $68(0.9)$ & $27(1.1)$ & 0.28 \\
\hline ICU Readmission within 72 hours & $\begin{array}{l}156 \\
(1.5)\end{array}$ & $116(1.5)$ & $40(1.6)$ & 0.57 \\
\hline \multicolumn{5}{|l|}{ ICU length of stay (days) } \\
\hline ICU Alive - Mean (SD) & $6.3(8.4)$ & $6.2(8.2)$ & $6.7(8.7)$ & $<0.001$ \\
\hline Median (IQR) & $\begin{array}{l}3.8(1.9- \\
7.5)\end{array}$ & $\begin{array}{l}3.7(1.9- \\
7.2)\end{array}$ & $\begin{array}{l}4.0(2.0- \\
8.2)\end{array}$ & \\
\hline \multicolumn{5}{|l|}{ ICU length of stay $\geq 7$ days, $n$ (\%) } \\
\hline Hospital Alive & $\begin{array}{l}2490 \\
(88.9)\end{array}$ & $\begin{array}{l}1846 \\
(89.4)\end{array}$ & $644(87.4)$ & 0.14 \\
\hline Hospital Dead & $\begin{array}{l}312 \\
(11.1)\end{array}$ & $219(10.6)$ & $93(12.6)$ & \\
\hline \multicolumn{5}{|l|}{ Hospital length of stay ${ }^{b}$ (days) } \\
\hline Hospital Alive - Mean (SD) & $\begin{array}{l}28.2 \\
(42.4)\end{array}$ & $\begin{array}{l}27.1 \\
(41.9)\end{array}$ & $\begin{array}{l}31.8 \\
(43.9)\end{array}$ & $<0.001$ \\
\hline Median (IQR) & $\begin{array}{l}14.0 \\
(7.0- \\
31.0)\end{array}$ & $\begin{array}{l}14.0(7.0- \\
29.0)\end{array}$ & $\begin{array}{l}16.0(8.0- \\
36.0)\end{array}$ & \\
\hline Hospital Dead - Mean (SD) & $\begin{array}{l}46.1 \\
(65.3)\end{array}$ & $\begin{array}{l}46.2 \\
(66.3)\end{array}$ & $\begin{array}{l}45.8 \\
(62.6)\end{array}$ & 0.93 \\
\hline Median (IQR) & $\begin{array}{l}26.0 \\
(13.0- \\
55.0)\end{array}$ & $\begin{array}{l}26.0(13.0- \\
54.0)\end{array}$ & $\begin{array}{l}26.0 \\
(12.0- \\
57.0)\end{array}$ & \\
\hline \multicolumn{5}{|l|}{ Post-ICU length of stayb (days) } \\
\hline Hospital Alive - Mean (SD) & $\begin{array}{l}19.2 \\
(35.0)\end{array}$ & $\begin{array}{l}18.3 \\
(34.6)\end{array}$ & $\begin{array}{l}22.2 \\
(36.4)\end{array}$ & $<0.001$ \\
\hline Median (IQR) & $\begin{array}{l}8.0(2.9- \\
19.2)\end{array}$ & $\begin{array}{l}7.9(2.8- \\
18.9)\end{array}$ & $\begin{array}{l}9.5(3.7- \\
22.7)\end{array}$ & \\
\hline
\end{tabular}




Hospital Dead - Mean (SD)
Median (IQR)
$\begin{aligned} & \text { Definition of abbreviation: IQR=interquartile range; } \\ & \text { LOS=Length of Stay; SD=standard deviation }\end{aligned}$
a Survival status in ICU.
b Survival status in hospital.

Table 4 Association of afterhours ICU discharge and hospital mortality - multivariate analysis with full adjustment. 


\begin{tabular}{|c|c|c|c|}
\hline Effect & $\begin{array}{l}\text { Unadjusted-OR } \\
(95 \% \mathrm{Cl})\end{array}$ & $\begin{array}{l}\text { Adjusted-OR } \\
(95 \% \mathrm{Cl})\end{array}$ & p-value \\
\hline Intercept & & & $<0.001$ \\
\hline Afterhours Discharge (19:00h-07:59h) & $1.15(0.99,1.34)$ & $1.19(1.01,1.39)$ & 0.04 \\
\hline \multicolumn{4}{|l|}{ Age } \\
\hline Age $<65$ years & Reference & Reference & \\
\hline Age 65-74 years & $2.39(2.00,2.85)$ & $1.97(1.63,2.38)$ & $<0.001$ \\
\hline Age 74-84 years & $3.73(3.13,4.44)$ & $3.10(2.55,3.76)$ & $<0.001$ \\
\hline Age $\geq 85$ years & $6.23(4.84,8.03)$ & $5.53(4.22,7.26)$ & $<0.001$ \\
\hline \multicolumn{4}{|l|}{ Hospital type } \\
\hline Academic & Reference & Reference & \\
\hline Community & $2.71(2.24,3.27)$ & $3.91(2.15,7.16)$ & 0.009 \\
\hline Tertiary & $1.62(1.39,1.90)$ & $1.75(0.88,3.46)$ & 0.19 \\
\hline \multicolumn{4}{|l|}{ System } \\
\hline Cardiovascular & Reference & Reference & \\
\hline Gastrointestinal & $1.10(0.89,1.36)$ & $1.10(0.86,1.40)$ & 0.44 \\
\hline Genitourinary & $0.52(0.34,0.81)$ & $0.52(0.33,0.83)$ & 0.006 \\
\hline Hematology & $0.77(0.32,1.88)$ & $0.77(0.28,2.10)$ & 0.60 \\
\hline Metabolic/Endocrine & $0.27(0.13,0.58)$ & $0.46(0.22,1.00)$ & 0.05 \\
\hline Musculoskeletal/Skin & $0.69(0.48,1.00)$ & $1.16(0.79,1.71)$ & 0.44 \\
\hline Neurologic & $0.44(0.34,0.58)$ & $0.55(0.39,0.78)$ & 0.001 \\
\hline Respiratory & $0.75(0.61,0.92)$ & $1.05(0.84,1.30)$ & 0.68 \\
\hline Transplant & $0.22(0.08,0.58)$ & $0.32(0.11,0.91)$ & 0.03 \\
\hline Trauma & $0.25(0.17,0.35)$ & $0.58(0.34,0.98)$ & 0.04 \\
\hline \multicolumn{4}{|l|}{ Surgery } \\
\hline Non-operative & Reference & Reference & \\
\hline Elective surgical & $0.42(0.31,0.56)$ & $0.46(0.30,0.69)$ & $<0.001$ \\
\hline Emergent surgical & $0.98(0.82,1.17)$ & $0.86(0.63,1.17)$ & 0.35 \\
\hline Class & & & \\
\hline
\end{tabular}




\begin{tabular}{|llll|}
\hline Medical & Reference & Reference & \\
\hline Neurological & $0.83(0.64,1.07)$ & $2.17(1.54,3.12)$ & $<0.001$ \\
\hline Surgical & $0.82(0.70,0.96)$ & $1.43(1.07,1.93)$ & 0.02 \\
\hline Trauma without head injury & $0.18(0.11,0.32)$ & $0.74(0.36,1.50)$ & 0.40 \\
\hline Trauma with head injury & $0.32(0.18,0.56)$ & $1.09(0.53,2.27)$ & 0.81 \\
\hline Comorbidity & & & \\
\hline Hepatic & $1.54(1.25,1.90)$ & $0.79(0.60,1.05)$ & 0.10 \\
\hline Neurologic & $1.25(1.08,1.43)$ & $1.20(1.01,1.42)$ & 0.04 \\
\hline Respiratory & $1.81(1.51,2.18)$ & $1.53(1.25,1.87)$ & $<0.001$ \\
\hline Metastatic/ Leukemia/Lymphoma & $1.83(1.48,2.27)$ & $1.63(1.28,2.06)$ & $<0.001$ \\
\hline Immune Suppression & $1.65(1.36,2.02)$ & $1.49(1.19,1.86)$ & $<0.001$ \\
\hline Diabetes Mellitus & $1.76(1.51,2.06)$ & $1.30(1.10,1.53)$ & 0.002 \\
\hline Cirrhosis & $2.23(1.81,2.76)$ & $2.18(1.66,2.88)$ & $<0.001$ \\
\hline Admission APACHE II score & $1.08(1.07,1.09)$ & $1.02(1.02,1.03)$ & 0.002 \\
\hline Invasive Ventilation & $1.01(1.01,1.02)$ & $1.02(1.01,1.03)$ & $<0.001$ \\
\hline Intubation & $1.03(1.02,1.04)$ & $1.02(1.01,1.04)$ & 0.01 \\
\hline Average SOFA score 72 hours before discharge & $1.26(1.23,1.30)$ & $1.23(1.18,1.28)$ & $<0.001$ \\
\hline
\end{tabular}

Table 5 Stratified analysis of the association between afterhours discharge and hospital mortality across selected exploratory subgroups - multivariate analysis with full adjustment. 


\begin{tabular}{|c|c|c|c|c|}
\hline Scenarios & $\begin{array}{l}\# \\
\text { observations }\end{array}$ & $\begin{array}{l}\text { Unadjusted } \\
\text { OR (95\% Cl) }\end{array}$ & $\begin{array}{l}\text { Adjusted-OR } \\
(95 \% \mathrm{Cl})\end{array}$ & $\begin{array}{l}\mathrm{p}- \\
\text { value }\end{array}$ \\
\hline \multicolumn{5}{|l|}{ Holiday/weekend } \\
\hline Workdays & 7595 & $\begin{array}{l}1.24(1.04 \\
1.48)\end{array}$ & $\begin{array}{l}1.24(1.04- \\
1.48)\end{array}$ & 0.02 \\
\hline Holiday/weekend & 2868 & $\begin{array}{l}0.85(0.60 \\
1.20)\end{array}$ & $\begin{array}{l}0.91(0.64- \\
1.31)\end{array}$ & 0.63 \\
\hline \multicolumn{5}{|l|}{ ICU occupancy prior to discharge } \\
\hline Occupancy $\geq 90 \%$ & 4919 & $\begin{array}{l}1.05(0.81 \\
1.35)\end{array}$ & $\begin{array}{l}1.07(0.85- \\
1.34)\end{array}$ & 0.58 \\
\hline Occupancy < 90\% & 5544 & $\begin{array}{l}1.21(0.99 \\
1.47)\end{array}$ & $\begin{array}{l}1.26(1.01- \\
1.58)\end{array}$ & 0.04 \\
\hline \multicolumn{5}{|l|}{$\begin{array}{l}\text { Clustering of ICU admission within } 2 \\
\text { hours of discharge time }\end{array}$} \\
\hline With clustering admission $(\geq 2)$ & 1354 & $\begin{array}{l}0.96(0.64 \\
1.45)\end{array}$ & $\begin{array}{l}1.00(0.65- \\
1.54)\end{array}$ & 1.00 \\
\hline Without clustering admission $(<2)$ & 9093 & $\begin{array}{l}1.19(1.01 \\
1.41)\end{array}$ & $\begin{array}{l}1.19(1.00- \\
1.41)\end{array}$ & 0.05 \\
\hline
\end{tabular}

Note: Estimate (SE) = estimated effect (standard error) of the exposure (afterhours discharge) on hospital mortality; OR $(95 \% \mathrm{Cl})=$ odds ratio $(95 \%$ confidence interval) of the estimate effect.

\section{Figures}




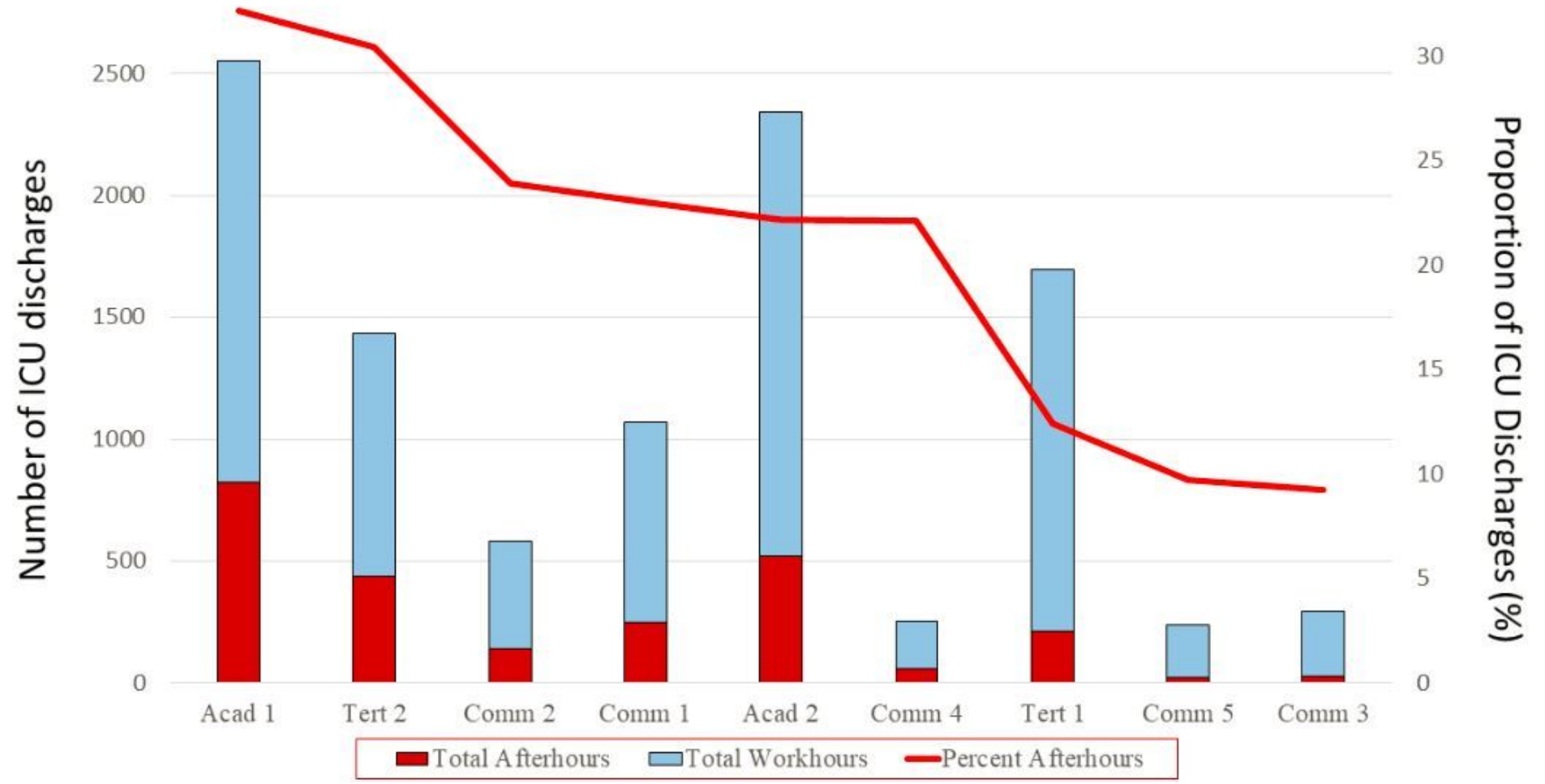

Figure 1

Proportion of discharges occurring afterhours, stratified by ICU (descending order).

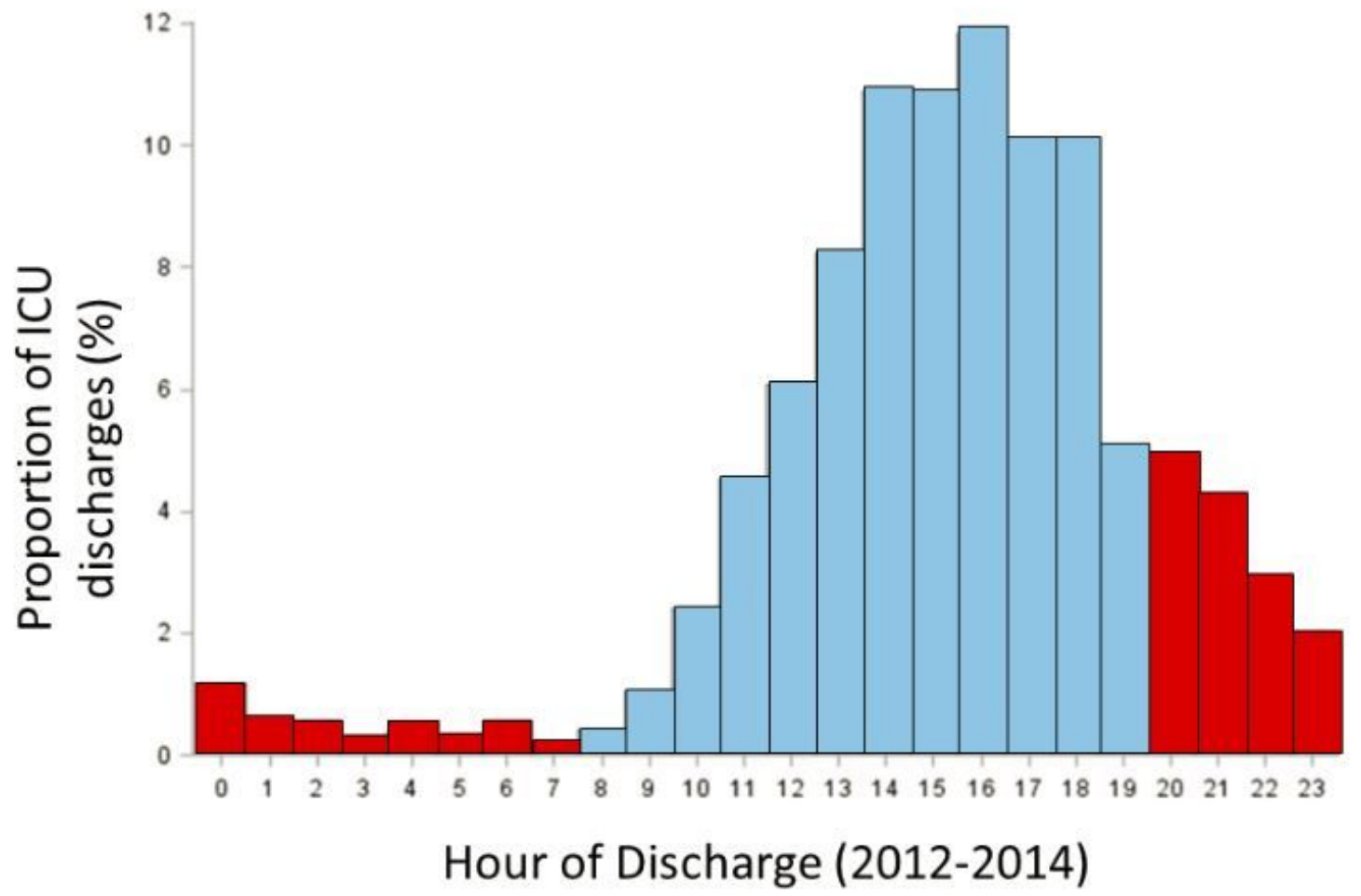


Figure 2

Proportion of patients discharged from ICU, stratified by hour. LEGEND: Red bars represent afterhours discharge and Blue bars represent daytime discharge.

\section{Supplementary Files}

This is a list of supplementary files associated with this preprint. Click to download.

- CritCareDischargeAfterhoursSupplementJuly272020.docx 